\title{
Selective Synthesis and Characterization of Single Walled Carbon Nanotubes $(11,8)$
}

\author{
Danlami Umar Zuru, Bala Hassan, Muhammad Nuraddeen Bui, Aliyu Sa’ad BK, \\ Aliyu Jabbo Bunzah
}

Department of Chemistry, School of Sciences, Adamu Augie College of Education, Argungu, Nigeria

Email address:

duzuru2013@gmail.com (D. U. Zuru)

\section{To cite this article:}

Danlami Umar Zuru, Bala Hassan, Muhammad Nuraddeen Bui, Aliyu Sa'ad BK, Aliyu Jabbo Bunzah, Selective Synthesis and Characterization of Single Walled Carbon Nanotubes (11, 8). International Journal of Materials Science and Applications.

Vol. 8, No. 2, 2019, pp. 25-29. doi: 10.11648/j.ijmsa.20190802.12

Received: April 2, 2019; Accepted: May 9, 2019; Published: July 4, 2019

\begin{abstract}
Single walled carbon nanotubes (SWCNTs) are attractive in the nanotechnology industry where they find applications in the field of pharmacy and medicine due to high surface area capable of transporting drugs and vaccines to active sites; for fabrication of energy storing devices due to excellent electrical conductivity and accessible pore sizes; in transport for the fabrication of strong and lightweight vehicle and aircraft parts and in composite materials to enhance physical and chemical properties such as toughness, durability, conductivity and strength. The most efficient and cost effective method of obtaining these precious materials is the Chemical Vapour Deposition (CVD), however, obtaining SWCNTs of desired electronic type via this method, has remained a global challenge for over 20 years. This has limited the availability of these products in the global research and technological industries, contributing to the problem of lack of raw materials to sustain them. In this report, metallic SWCNTs $(11,8)$ are selectively synthesized via chemical vapor deposition (CVD) method, by the pyrolysis of $\mathrm{C}_{6} \mathrm{H}_{14} / \mathrm{N}_{2}$ feedstock on $\mathrm{Fe}_{2} \mathrm{O}_{3} / \mathrm{Al}_{2} \mathrm{O}_{3}$ catalyst matrix. Catalyst design and preparation was achieved by correlating the numerical magnitudes of chiral index (n, m) of the desired SWCNTs with mole fractions of metal/support, respectively. Field emission scanning electron microscopy analysis reveals densely entangled tubular bundles, while high resolution transmission electron microscopy confirms rigid arrangements of SWCNTs in the bundles. Values of the radial breathing modes, diameter and energy band gaps of the sample obtained from Raman analysis conforms to that of SWCNTs $(11,8)$, established via Extended Tight Binding (ETB) model. Outcome of this report suggested that our catalyst design and preparation may help alleviate the stated global challenge.
\end{abstract}

Keywords: CVD, Selective Synthesis, SWCNTs $(11,8)$, Catalyst, ETB Model

\section{Introduction}

Single walled carbon nanotubes (SWCNTs) are generally formed by rolling a single graphene sheet into a seamless cylinder, which makes it very difficult and expensive to produce for commercial application [1]. These materials are reported to exhibit metallic or semiconducting character, depending on the orientation of a chiral vector composing of two chiral index (n, m), which signifies a unique molecule of SWCNT and hence determines the thermal, optical, mechanical, electronic and magnetic properties of the material [2]. The carbon materials are also reported to be attractive in the nanotechnology industry as they poses excellent mechanical properties, and are therefore applied in composite materials to enhance physical and chemical properties such as toughness, durability, conductivity and strength; their sensing abilities enabled them have potential applications in environmental, medical and agricultural studies; their good electrical conductivity and pore sizes suitable for storing electrolyte ions, also made them attractive in the field of electronics [3]. The need to produce these materials of desired chirality is therefore of utmost importance. Modern research reports on selective synthesis of single walled carbon nanotubes (SWCNTs) via Chemical Vapor Deposition (CVD) method using catalysts were based on the in situ epitaxial growth model, which attributed the dependence of SWCNT growth control on the crystal size or 
structure of the catalyst nano particles. However, the feasibility of obtaining nano particles of same sizes, shape and high thermal stability are the limiting factors that undermine the effectiveness and efficiency of this method. This has necessitated the need for new innovative approaches that are more simple and cost effective, which may be used to selectively grow SWCNTs of desired chirality [4].

We have proposed and reported both theoretical and experimental models for selective synthesis of SWCNTs [5]. In the current report, we design and prepare $\mathrm{Fe}_{2} \mathrm{O}_{3} / \mathrm{Al}_{2} \mathrm{O}_{3}(11$, 8) catalyst matrix based on our model prediction, in order to selectively grow the corresponding SWCNTs $(11,8)$. Raman spectroscopy was used to analyze the purity and electronic properties of the as-grown SWCNTs, been the most powerful tool for such determinations [2-6]. X-ray diffraction (XRD), field emission scanning electron microscopy (FESEM), transmission electron microscopy (TEM) and high resolution transmission electron microscopy (HRTEM) analyses were performed to compliment the Raman analysis.

\section{Material and Methods}

\subsection{Catalyst Preparation}

The amount of $\mathrm{Fe}\left(\mathrm{NO}_{3}\right)_{3} .9 \mathrm{H}_{2} \mathrm{O}$ and $\mathrm{Al}\left(\mathrm{NO}_{3}\right)_{3} .9 \mathrm{H}_{2} \mathrm{O}(98 \%$; Fisher) precursor salts needed to obtain the corresponding $\mathrm{Fe}_{2} \mathrm{O}_{3} / \mathrm{Al}_{2} \mathrm{O}_{3}$ oxide catalyst of compositions $(11,8)$ was estimated using equation (1)

$$
M_{s}=\frac{W_{s} \times O_{m}}{w_{o} \times p_{s}}
$$

Where $M_{s}, W_{s}, O_{m}, w_{o}$ and $p_{s}$ are the amounts of precursor salt, molecular weight of precursor salt, amount of metal or support oxide needed to obtain the desired SWCNT, molecular weight of metal or support oxide and percentage purity of precursor salt, respectively.

Hence, to prepare $(11,8)$ catalyst, about $28 \mathrm{~g}$ of $\mathrm{Fe}\left(\mathrm{NO}_{3}\right)_{3} \cdot 9 \mathrm{H}_{2} \mathrm{O}$ was dissolved in $100 \mathrm{~mL}$ distilled water in a conical flask and stirred for 30 minutes, $30 \mathrm{~g}$ of $\mathrm{Al}\left(\mathrm{NO}_{3}\right)_{3} \cdot 9 \mathrm{H}_{2} \mathrm{O}$ was then added into the resulting solution and the mixture stirred for two hours, then left for another 24 hours, in order to achieve homogeneity. The nitrate solution was then dried for 48 hours at an adjusted temperature of $90^{\circ} \mathrm{C}$. Calcination was performed in a Vulcan furnace at $450^{\circ} \mathrm{C}$ under air circulation for two hours; at a heating rate of $5^{\circ} \mathrm{C} / \mathrm{min}$. Solid products were finally cooled to room temperature, manually grounded, stored in sample bottles and labeled as Cat. $(11,8)$.

\subsection{Synthesis of SWCNTS}

Pyrolysis of $\mathrm{C}_{6} \mathrm{H}_{14} / \mathrm{N}_{2}$ feedstock on Cat. $(11,8)$ was carried out in a split type horizontal furnace (LT Furnace STF-301200 model) at $1000^{\circ} \mathrm{C}$, under nitrogen gas flow rate of 100 $\mathrm{mL} / \mathrm{min}$. About 0.5 gram of the catalyst was loaded in an alumina boat and the pyrolysis time was set for $30 \mathrm{~min}$. at $0.06 \mathrm{~mL} / \mathrm{min}$. Resulting products were then cooled, scraped into sample bottles and labeled as $\operatorname{SWCNT}(11,8)$.

\subsection{Catalyst and SWCNT Characterization}

The X-ray diffraction patterns of the catalyst and SWCNTs were obtained using an XRD-6000 powder diffract meter of $\mathrm{CuK}_{\alpha}$ radiation $(\lambda=0.15406 \dot{\mathrm{A}})$ operated at $40 \mathrm{kV}$ and 30 $\mathrm{mA}$ at $4^{\circ} \mathrm{C} \mathrm{min}^{-1}$. Resulting data analyses were performed using an $\mathrm{X}^{\prime}$ Pert High score PAN analytical software version $1.0 \mathrm{~d}$, via Shearer equation. Morphology of the sample was analyzed using a field-emission-scanning electron microscopy (FESEM) (FEI Nova Nanosem 230), operated at $15 \mathrm{kV}$. High resolution transmission electron microscopy (HR-TEM) analysis of the SWCNTs sample was performed using a Zeiss EM 902A. Raman analysis of as-grown products was obtained with a WITec Alpha 300R Raman spectrometer, using a laser excitation wavelength of $532 \mathrm{~nm}$, corresponding to $2.3 \mathrm{eV}$, in which only metallic SWCNTs were resonant [8]; the resulting radial breathing modes (RBMs) obtained were used to estimate the diameter $\left(\mathrm{d}_{\mathrm{t}}\right)$ and the band gap ( $\left.E_{11}\right)$, using equations (2) and (3), respectively, [2-8].

$$
\begin{aligned}
& d_{t}=\frac{248}{\omega R B M} \\
& E_{11}=\frac{6 a_{c c} \gamma_{\bullet}}{d_{t}}
\end{aligned}
$$

Where $\omega R B M, a_{c c}, \gamma_{\bullet}$ and $d_{t}$ are respectively, the radial breathing mode, $\mathrm{C}-\mathrm{C}$ distance $(0.1421 \mathrm{~nm})$, nearest neighbor hoping parameter $(2.9 \mathrm{eV})$ and diameter.

\section{Results and Discussion}

\subsection{Analysis of Cat. $(11,8)$}

The sample catalyst showed diffraction peaks at $2 \Theta=$ $24.2^{\circ}, 33.3^{\circ}, 35.6^{\circ}, 41.0^{\circ}, 49.6^{\circ}, 54.2^{\circ}, 62.6^{\circ}$ and $64.2^{\circ}$, corresponding to (012), (104), (110), (113), (024), (116), (214) and (300) reflections of hematite iron oxide, $\alpha-\mathrm{Fe}_{2} \mathrm{O}_{3}$, respectively, (JCPD no. 03-0664), $[11,12,13]$ as shown in Figure 1.

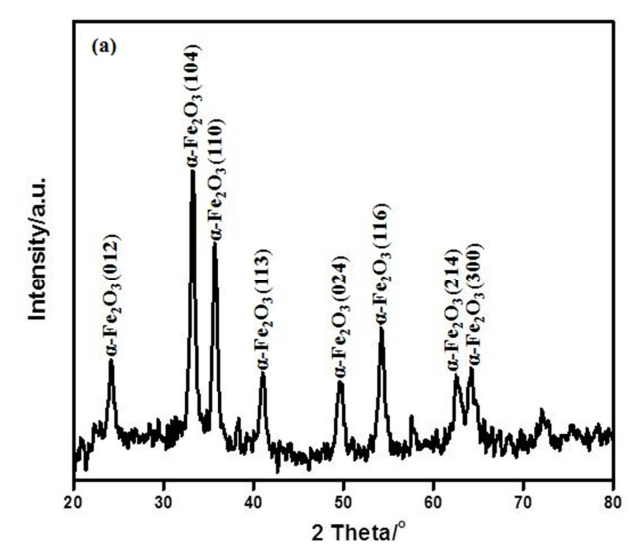

Figure 1. X-RD profile of Cat.(11, 8) showing different phases of $\alpha-\mathrm{Fe}_{2} \mathrm{O}_{3}$. 
The resulting FESEM morphological image of Cat.(11, 8) is shown in Figure 2, showing pellets of nano-sized particles with few larger agglomerations which suggested that metal/support catalyst interaction is highly enhanced at $450^{\circ} \mathrm{C}$.

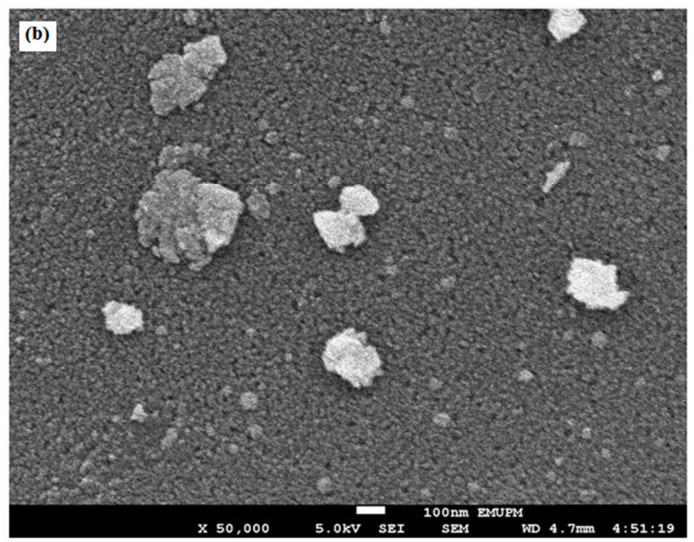

Figure 2. FESEM image of Cat. $(11,8)$ showing nano sized pellets of particles with few agglomeration.

\subsection{Analysis of SWCNT $(11,8)$}

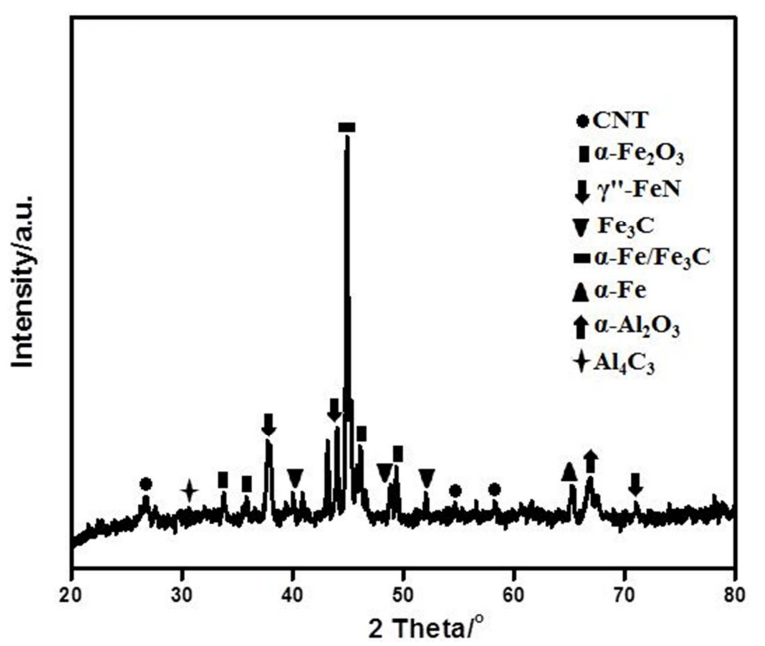

Figure 3. $X-R D$ profile of $\operatorname{SWCNTS}(11,8)$ showing metal carbides and nitrides in addition to $S W C N T$ s.

Figure 3 was a plot of XRD profile of SWCNTs $(11,8)$. Prominent peaks of graphitized SWCNTs were recorded at $2 \Theta($ degree $)=26.6,54.4$ and 59.5, corresponding to hexagonal reflections of C (002), C (004) and C (102), respectively, (JCPDS file no. 75 -1621) [14]. Peaks in the range 31.1-32.0 were attributed to reflection of $\mathrm{Al}_{4} \mathrm{C}_{3}$ (201) (JCPDS file no. 6-696) [15]. Reflections of $\alpha-\mathrm{Fe}_{2} \mathrm{O}_{3}$ (104), (113) and (011) appeared at 33.5, 42.9 and 43.1, respectively, (ICDD file no. $10-10425$ ) [15], while 37.8, 44.7 and 70.9 were peaks of $\gamma^{\prime \prime}-\mathrm{FeN}$ (111), (021) and (013), respectively, (JCPDS file no. 34 -1) [16]. Reflections at 39.9 and 49.2 was attributed to $\mathrm{Fe}_{3} \mathrm{C} \mathrm{(221)} \mathrm{and} \mathrm{(220),} \mathrm{respectively} \mathrm{(JCPDS} \mathrm{file}$ no. $6-696 ; 34-1)$, and those occurring in the range 45.245.9.4 were those of $\alpha-\mathrm{Fe}(110)$ and $\mathrm{Fe}_{3} \mathrm{C}$ (220) overlap (JCPDS file no. 6 -696; $34-1$ ) [17]. Peaks in the range 66.3-
66.9 were reflections of $\alpha-\mathrm{Al}_{2} \mathrm{O}_{3}$ (440) (ICDD file no. 10 0425) [18]. Reflections of C (002), C (102) and C (004) was a suggestion that the samples contained pure graphitized carbon atoms arranged in a hexagonal matrix structure [19]. Appearances of $\mathrm{Al}_{4} \mathrm{C}_{3}, \mathrm{Fe}_{3} \mathrm{C}$ and $\gamma^{\prime \prime}-\mathrm{FeN}$ moieties on the sample SWCNTs may suggest that growth occurred on surface of the reduced catalyst, and the decomposition of $\mathrm{C}_{6} \mathrm{H}_{14} / \mathrm{N}_{2}$ feedstock on the $\mathrm{Fe}_{2} \mathrm{O}_{3} / \mathrm{Al}_{2} \mathrm{O}_{3}$ catalyst matrixes might have been responsible for the production of atomic $\mathrm{C}$, $\mathrm{N}$ and $\mathrm{H}$. Bonding of $\mathrm{N}$ and $\mathrm{C}$ atoms to $\mathrm{Fe}$ metal was observed to proceed via strong $\mathrm{p}-\mathrm{d}$ covalent bonding, and the charge transfer from $\mathrm{Fe}$ to these atoms is responsible for the molecular stability of the composites [1].

Carbides and nitrides composites were also reported to show synergetic effect on the chemical stability and corrosion resistance of the samples, which results in better selectivity, catalytic capability and resistance to poisoning, as compare to their parents metal [20].

The FESEM image of the $\operatorname{SWCNT}(11,8)$ sample is displayed in Figure 4, revealing forest of long entangled tubes, while Figure 5 shows the HR-TEM images, displaying partially debundled SWCNTs.

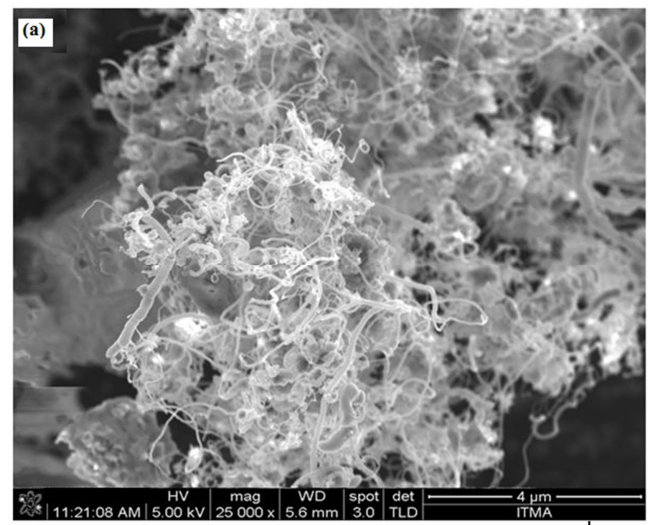

Figure 4 FESEM image of $\operatorname{SWCNTS}(11,8)$ showing densely entangled network.
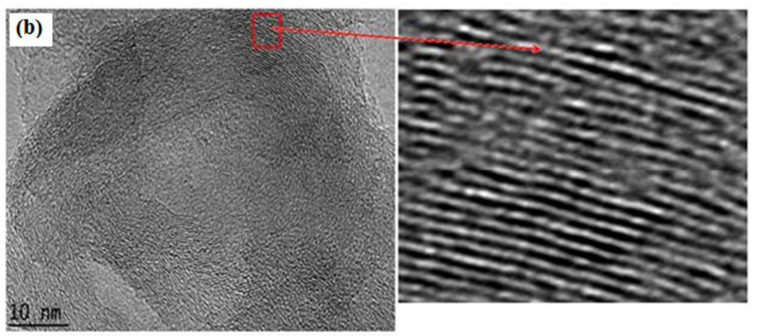

Figure 5. HR-TEM image showing partially dispersed bundle.

It is a documented fact that obtaining separated SWCNTs during CVD synthesis has not being thermodynamically feasible, due to their high polarization and smooth surface which causes strong van der Waal's interaction $(\sim 500 \mathrm{eV})$ and $\pi-\pi$ intertube stacking, resulting to formation of large agglomerated bundles and ropes [21-22]. Additionally, the carbide moieties may have polymerized over the sample SWCNTs, as shown in their TEM image of Figure 6, which may also increase the surface tension and therefore the 
hydrophobicity of the as-grown SWCNTs which resulted in poor dispersion of the sample [7].

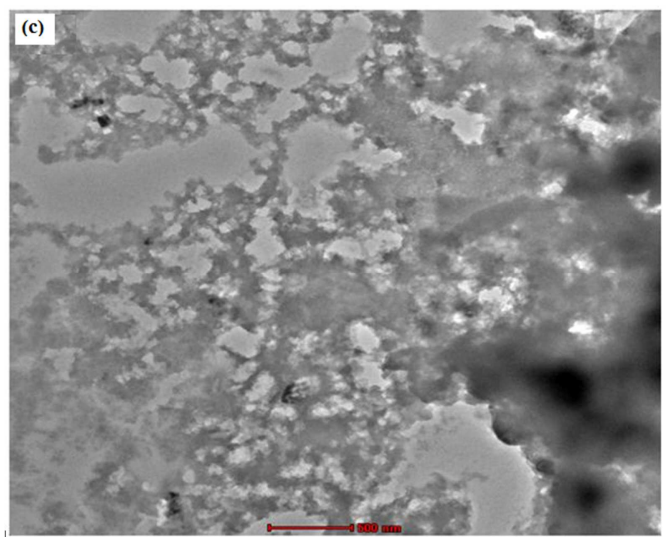

The values of Raman RBMs, estimated diameter $\left(d_{t}\right)$ and energy band gap $\left(\mathrm{E}_{11}\right)$ recorded of samples $\operatorname{SWCNT}(11,8)$ were compared with those established by the ETB model and presented in "Table 1". Sample SWCNTs $(11,8)$ showed RBM resonance $\left(\mathrm{cm}^{-1}\right)$ within the range 100-300, indicating the signature of single wall carbon nanotubes [2]. The RBM value of SWCNTs $(11,8)$ showed $16 \%$ deviation from the ETB values, and diameter deviation of $8 \%$. The energy band gap of the sample falls within the range 1.7-2.7 eV, for metallic transitions, which suggested that the synthesized SWCNTs are metallic [8]. The deviations recorded for the two samples were within acceptable experimental limit of $<$ $20 \%$ [23] and may be due to the inability of the ETB model to account for the curvature effects occurring in SWNTs with smaller diameter [24].

Figure 6. TEM image showing possible polymerization of carbide on SWCNTS surface which restrict dispersion.

Table 1. ETB values Vs. Current Values for $\operatorname{SWCNTS}(11,8)$.

\begin{tabular}{|c|c|c|c|c|c|c|c|}
\hline \multirow{2}{*}{ Sample } & \multirow{2}{*}{ Chiral Index $(\mathrm{n}, \mathrm{m})$} & \multirow{2}{*}{$\begin{array}{l}\text { ETB Values } \\
\text { RBM }\left(\mathrm{cm}^{-1}\right)\end{array}$} & \multicolumn{5}{|c|}{ Current Values } \\
\hline & & & Diameter (nm) & $E_{11}(\mathrm{eV})$ & $\operatorname{RBM}\left(\mathrm{cm}^{-1}\right)$ & Diameter (nm) & $E_{11}(e V)$ \\
\hline SWCNT & $(11,8)$ & 184 & 1.3 & 1.9 & 214 & 1.2 & 2.2 \\
\hline
\end{tabular}

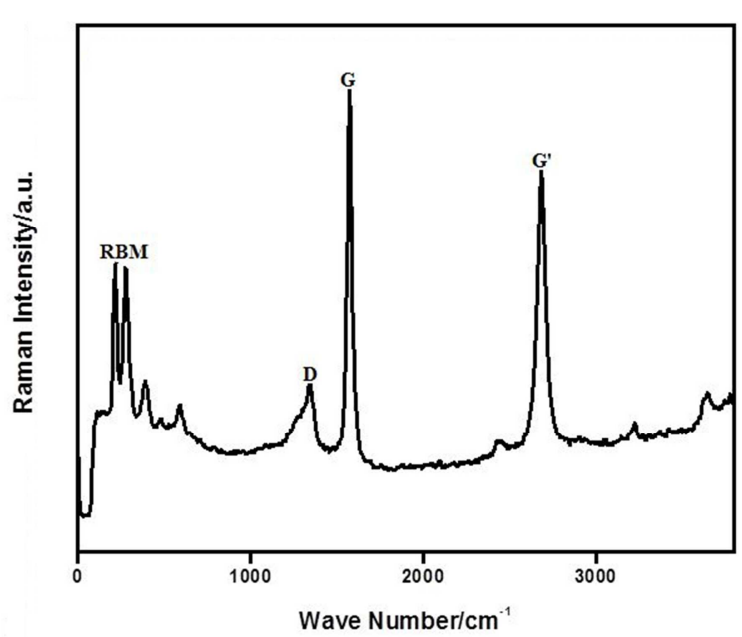

Figure 7. Raman profile of SWCNTs $(11,8)$ showing the important features.

Figure 7 was the plot of Raman profile for SWCNTs (11, 8). The additional RBM at $277 \mathrm{~cm}^{-1}$ was a suggestion that part of sample might have been photo oxidized by the high laser intensity of green (visible) light at $532 \mathrm{~nm}(2.3 \mathrm{eV})$, used in this analysis [25]. The D- and G- bands of sample appeared at $1343 \mathrm{~cm}^{-1}$ and $1573 \mathrm{~cm}^{-1}$, respectively, and the estimated ID/IG value was 0.3 , indicating high levels of graphitization. The $\mathrm{G}^{\prime}-$ band at $2670 \mathrm{~cm}^{-1}$ and its strong intensity also signifies higher levels of purity and metallicity. Additional peaks appearing at $389 \mathrm{~cm}^{-1}$ and $588 \mathrm{~cm}^{-1}$ were reflections of $\mathrm{Al}$ and $\mathrm{Fe}$ impurities, respectively, [2].

\section{Conclusion}

Based on the fact that the catalyst determines the overall architecture of SWCNTs, this report correlated the magnitude of chiral index for SWCNT $(11,8)$ with mass fractions of $\mathrm{Fe}_{2} \mathrm{O}_{3} / \mathrm{Al}_{2} \mathrm{O}_{3}$ catalyst matrix, respectively, in order to selectively grow the corresponding products. The physicochemical analyses of the as-grown SWCNTs $(11,8)$ obtained in the current work shows acceptable deviations with the established ETB model results for the same product. This was a suggestion that if the CVD reaction and material parameters of our model method are optimized, it may serve to alleviate the use of the complex in-situ epitaxial growth model.

\section{Acknowledgements}

The funding by the Adamu Augie College of Education, Kebbi-State, Nigeria, is hereby acknowledged and appreciated; however, all ideas contained in this manuscript reflect the decision of the authors alone.

\section{References}

[1] H. Y. Yap, B. Ramaker, A. V. Sumant, R. W. Carpick, Growth of mechanically fixed and isolated vertically aligned carbon nanotubes and nanofibers by DC plasma-enhanced hot filament chemical vapor deposition. Diamond \& Related Materials, 15 (2006). 1622-1628.

[2] M. S. Dresselhaus, G. Dresselhaus, R. Saito, A. Jorio, Raman Spectroscopy of carbon nanotubes, Phys. Rep. 409 (2005) 47-99.

[3] M. A. Azam, A. Fujiwara, T. Shimoda, T, Significant Capacitance Performance of Vertically Aligned Single-walled Carbon Nanotube Supercapacitor by Varying Potassium Hydroxide Concentration. Int. J. Electrochem. Sci. 8 (2013). 3902-3911. 
[4] B. Liu, F. Wu, H. Gui, M. Zheng, C. Zhou, Chiralitycontrolled synthesis and applications of single-wall carbon nanotubes, ACS Nano 11 (2017) 31-53.

[5] D. U. Zuru, Z. Zainal, M. Z. Hussein, A. M. Jaafar, H-N. Lim, S-K. Chang, Theoretical and experimental models for the synthesis of single walled carbon nanotubes and their electrochemical properties, J. Appl Electrochem (2018). https://doi.org/10.1007/s10800-018-1158-6

[6] A. Md. Shamsul, Empirical equation based chirality (n, m) assignment of semiconducting single wall carbon nanotubes from resonant Raman scattering data. Nanomaterial. 3 (2013) $1-21$.

[7] Z. Weng, W. Liu, L.-C. Yin, R. Fang, M. Li, E. I. Altman, Q. Fan, F. Li, H.-M. Cheng, H. Wang, Metal/oxide interface nano-structures generated by surface segregation for electrocatalysis, Nano Lett. 15 (2015) 7704-7710.

[8] M. A. Pimenta, A. Marucci, J. A. Empedocles, M. G. Bawendi, E. B. Hanlon, A. M. Rao, P. C. Eklund, R. E. Smalley, G. Dresselhaus, M. S. Dresselhaus, Raman modes of metallic carbon nanotubes, Phys. Rev. B 58 (1998) 1-4.

[9] R. Jain, and S. Sharma, Glassy carbon electrode modified with multi-walled carbon nanotubes sensors for the quantification of antihistamine drug pheniramide in solubilized systems, Res. J. Chem. Sci., 1 (2011) $137-142$.

[10] J. H. Chen, W. Z. Li, D. Z. Wang, S. X. Yang, J. G. Wen, and Z. F. Ren, Electrochemical characterization of carbon nanotubes as electrode in electrochemical double-layer capacitors, Carbon, 40 (2002) 1193-1197.

[11] P. Liu, S. He, H. Wei, J. Wang, C. Sun, Characterization of $\alpha-$ $\mathrm{Fe}_{2} \mathrm{O}_{3} / \gamma-\mathrm{Al}_{2} \mathrm{O}_{3}$ catalysts for catalytic wet peroxide oxidation of m-cresol, Ind. Eng. Res. 54 (2015) 130-136.

[12] F. Gulshan, K. Okada, Preparation of alumina-iron oxide compounds by co-precipitation method and its characterization, American Journal of Material Sciences and Engineering 1 (2013) 6-11.

[13] C. Qin, X. Lu, G. Yin, Z. Jin, Q. Tan, X. Bai, Study of activated nitrogen-enriched carbon and nitrogen-enriched carbon/carbon aerogel composite as cathode materials for supercapacitors, Mater. Chem. Phys. 126 (2011) 453-458.

[14] M. Hermanek, R. Zboril, I. Medrik, J. Pechousek, C. Gregor, Catalytic efficiency of iron (III) oxides in decomposition of hydrogen peroxide: Competition between the surface area and crystallinity of nanoparticles, J. Am. Chem. Soc. 129 (2007) 10929-10936.
[15] B. V. Kumar, R. Thomas, A. Mathew, G. M. Rao, D. Mangalaraj, N. Ponpandian, C. Viswanathan, Effect of catalyst concentration on the synthesis of MWCNT by single step pyrolysis, Advanced Materials Letters 5 (2014) 543-548.

[16] W.-J. Yu, P.-X. Hou, L. L. Zheng, F. Li, C. Liu, H.-M. Cheng, Preparation and electrochemical property of $\mathrm{Fe}_{2} \mathrm{O}_{3}$ nano particles filled carbon nanotubes, Chem. Commun. 46 (2010) 8576-8578.

[17] L. Dumee, K. Sears, J. Schutz, A. Fim, M. Duke, S. Gray, Influence of sonication temperature on the debundling kinetics of carbon nanotubes in propan-2-ol. Nanomaterials 3 (2013) $70-85$.

[18] V. Krisyuk, A. N., Gleizes, L. Aloui, A. Turgambaeva, B. Sarapata, H. N. Prud, F. Senocq, D. Samelor, A. ZielinskaLipiec, D. deCaro, C. Vahlas, Chemical vapour decomposition of iron, iron carbides and iron nitride films from amidinate precursors, J. Electrochem. Soc. 157 (2010) D454-D461.

[19] D. J. Ham, J. S. Lee, Transition Metal Carbides and Nitrides as Electrodes Materials for Low Temperature Fuel Cells. Carbon. 7, (2009). 346.

[20] A. Oki, L. Adams, Z. Luo, E. Osayamon, P. Biney, V. Khabashesku, Functionalization of single-walled carbon nanotubes with N-[3-(trimethoxysilyl)Propyl]ethylenediamine and its Cobalt complex, J. Phys Chem Solids. 69 (2008) 11941198.

[21] D. A. Britz, A. N. Khlobystov, Non-covalent interactions of molecules with single walled carbon nanotubes, Chem. Soc. Rev. 35 (2006) 637-659.

[22] C. I. Nwoye, S. Ndlu, Model for predictive analysis of the concentration of phosphorus removed during leaching of iron oxide ore in sulphuric acid solution, Journal of Minerals and Materials Characterization and Engineering 8 (2009) 261-269.

[23] H. Somada, K. Hirahara, S. Akita, Y. Nakayama, A molecular linear motor consisting of carbon nanotubes, Nano Lett. 9 (2009) 62-65.

[24] J. H. Lehman, M. Terrones, E. Mansfield, K. E. Hurst, V. Meunier, Evaluating the characteristics of multiwall carbon nanotubes, Carbon 49 (2011) 2581-2602.

[25] J. P. Tessonier, and D. S. Su, Recent Progress on Growth Mechanism of Carbon Nanotubes: A review, ChemSuschem, 0000 (2011) 6-11. 